\title{
Application of Self Mass Damper in multi-story concrete building
}

\author{
Dina Rubiana Widarda ${ }^{1, *}$ and Maria Yvonne Hidajat $^{1}$ \\ ${ }^{1}$ Civil Engineering Department, Universitas Katolik Parahyangan, Bandung, Indonesia
}

\begin{abstract}
Comfort is one among several aspects in building design. Comfort of the occupant can be measured from the dynamic performance of the building during earthquake. This performance can be increased by installing vibration control to reduce dynamic responses of the building.

Considering the space-use efficiency, the building is utilizing certain floors to act as mass dampers. The floors are able to move back and forth independently to counter building vibration. Utilizing an existing floor slab as a mass damper is known as passive vibration control or in particularly named self mass damper (SMD).

A 14-story reinforced concrete building is modeled as a case study. The movable floor placement is varied in 3 configurations. The modeled building is excited by El Centro 1940 and Denpasar 1979 ground accelerations, independently. The study compares the dynamic responses of building without SMD and with SMD in three different placements.

Placing SMD in 4 top floors (13th,12th, 11th, 10th) gives the best result in reducing building's dynamic response compared to SMD in 4 mid-height floors (11th,10th, 8th, 7th) or separate group (13th, 12th, 6th, 5th). It is shown that the building has a tendency to response conforming 1 st mode of the building.

From the analysis, it can be concluded that applied SMD system gives greater reduction on building's displacement, velocity, and acceleration in response to Denpasar ground acceleration rather than El Centro 1940.
\end{abstract}

\section{Introduction}

Structural vibration damping can be produced from dampping elemen or damping system that consists of springmass system (tuned mass damper) or pendulum system. Tuned mass damper (TMD) is passive system that works effectively in the existence of resonance. TMD has been widely applied in several fields not only in structural engineering such as highrise buildings and bridges, but also in automobiles and spacecrafts.

Application of TMD in highrise building is intended to reduce vibration due to dynamic load such as earthquake or wind. TMD in the form of an instrument consists of mass and spring that is attached to main structure. The attachment of TMD will shift the natural frequency of structure.

Applying TMD in the building takes spaces, depends on the dimension of mass and its displacement range. One extreme example is Tapei 101 building that has $55 \mathrm{~m}$ diameter of hanging mass spans in 5 floors [1].

As the price of land in commercial areas keep rising, every square-inch is important. The building has to effectively utilize spaces whilst keeping the comfort of the tenant. The use of TMD will take valuable spaces, on the other hand the vibration of building should be limited.

Inspired by Nicolas G. Hayek Center [2], this paper simulated the placement of movable slab floor in 14 stories concrete building. The functional floor able in moving was treated as mass damper instrument. The system allowing its functional floor to vibrate independently to the main structure is named self mass damper (SMD).

\section{Design of SMD}

Optimum design of tuned mass damper (TMD) was discussed comprehensively in some references like book [3] or article [4].

Brief scheme of tuned mass design is written below

1. Choose the ratio of mass, $\mu$,

$$
0.01 \leq \mu \leq 0.05 \rightarrow m_{T}=\mu \cdot m,
$$

where $m$ is total mass of main structure and $m_{T}$ is mass of TMD.

2. Calculate the optimal $\alpha$-value

$$
\begin{aligned}
\alpha & =\frac{1}{1+\mu} \\
\alpha & =\frac{\omega_{T}}{\omega_{0}}=\sqrt{\frac{k_{T}}{m_{T}} \frac{m}{k}}
\end{aligned}
$$

where $\omega_{0}$ is natural frequency of main structure and $\omega_{T}$ is natural frequency of TMD. $k$ and $k_{T}$ denote stiffness of main structure and spring constant of TMD, respectively.

3. Accordingly put the optimal spring, $k_{T}$,

$$
k_{T}=\alpha^{2} \mu k=\frac{\mu}{(1+\mu)^{2}} k
$$

* corresponding author: dinarw@unpar.ac.id 
4. Calculate the optimal damping grade, $D_{\text {opt }}$,

$$
D_{o p t}^{2}=\frac{3 \mu}{8(1+\mu)^{3}}
$$

and the corresponding damping constant, $d_{o p t}$,

$$
d_{o p t}=2 D_{o p t} m_{T} \omega_{0}=\frac{\mu}{1+\mu} \sqrt{\frac{3 \mu}{2(1+\mu)} k m} .
$$

\section{Case study and discussion}

A 14-story concrete building taken as a case study is modelled as three dimensional open frame structure (Figure 2). The building has uniform plan of $12 \mathrm{~m} \times 30 \mathrm{~m}$. With floorto-floor heights is $4 \mathrm{~m}$ each, then the total height is $56 \mathrm{~m}$.

The study works on two sequential main objectives, there are:

1. Effective placement of SMD.

To study the placement of SMD, 4 structure model are done. The first structural model is normal building without SMD as shown in Figure 1(a), and the other three are buildings with SMD in different variation. There are 3 variation of SMD placement:

(a) SMD 1: Slab of 13th,12th, 11th, 10th floor is designed as movable slab as shown in Figure $1(\mathrm{~b})$;

(b) SMD 2: 11th,10th, 8th, 7th floor is designed as movable slab as shown in Figure 1(c);

(c) SMD 3: 13th, 12th, 6th, 5th floor is designed as movable slab as shown in Figure 1(d).

Effective placement of SMD is determined by the most reduced response due to harmonic loading. Harmonic loading imposed to structure is sinusoidal which tunned to the first natural frequency of building.

2. Dynamic response simulation of building with SMD due to El Centro 1940 and Denpasar ground motion acceleration

The considered effective configuration of SMD placement due to sinusoidal acceleration then imposed by El Centro and Denpasar ground motion acceleration. Both El Centro and Denpasar ground acceleration is scaled to Indonesian earthquake spectra.

Considering the needs of slab thickness that should meet stiffness, strength and stability condition, the SMD design scheme is modified. Instead of taken mass ratio as prescribed value (as per first step of scheme above), the mass ratio is determined from the designed slab. As a result, total mass ratio is $26 \%$.

Movable slab layout dan structural model is shown in Figure 3. SMD consists of 5 (five) movable slab in one floor.

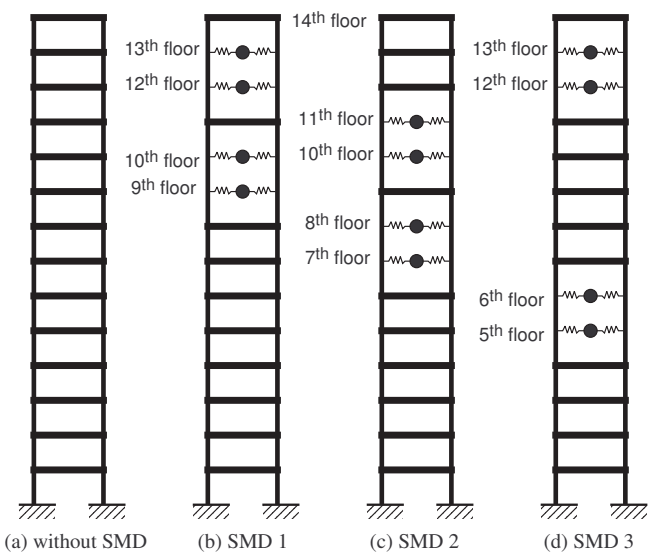

Figure 1. Moveable slab placement type on building.

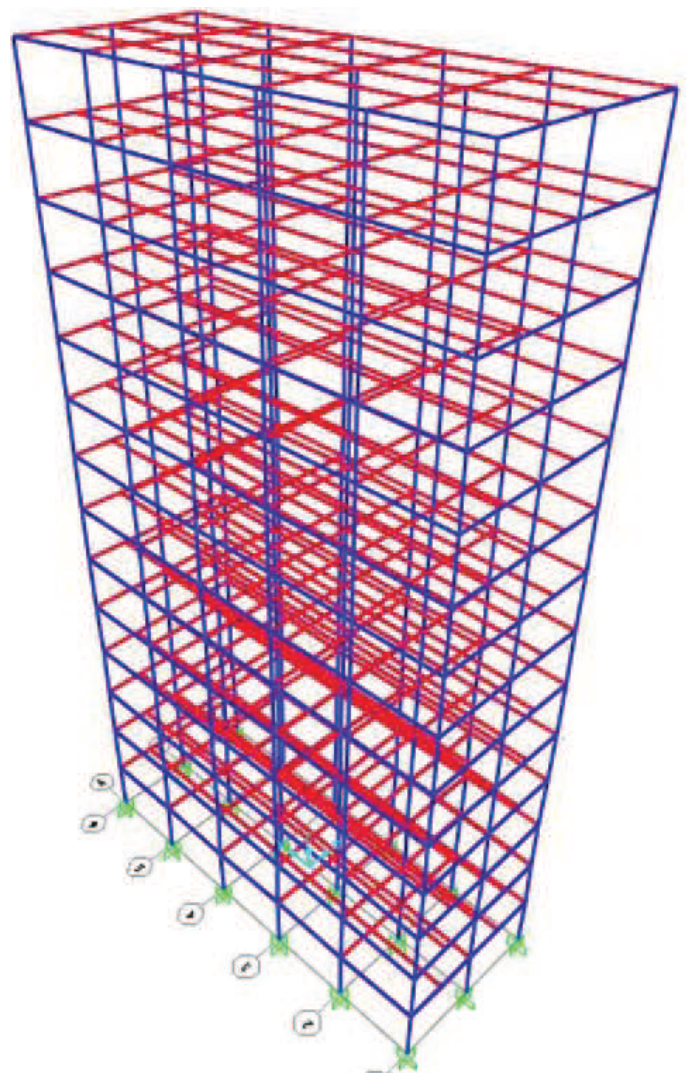

Figure 2. Concrete frame model.

\subsection{Due to sinusoidal ground acceleration}

By applying the SMD, the natural frequencies of main structure is shifting to avoid resonance. In order to evaluate structure responses due to SMD, sinusoidal acceleration that resonance with the first natural frequency is generated. The structure responses due to this harmonic signal are considered to determine the effectiveness of the SMD.

Due to sinusoidal acceleration that resonance with the first natural frequency, building story displacement reduces in average 56\% for SMD 1, 53\% for SMD 2 and $47 \%$ for SMD 3 (Table 1). Story horizontal velocity re- 


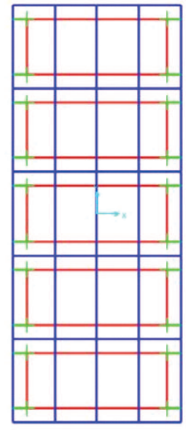

(a) Slab layout.

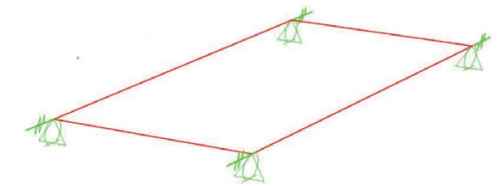

(b) Slab structural model with restraint.
Figure 3. Floor layout and slab structural model.

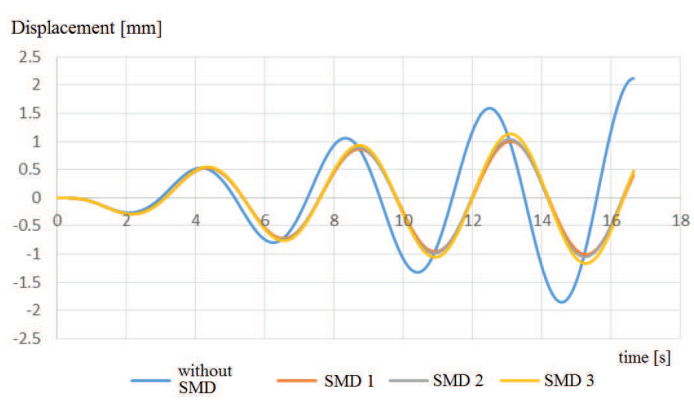

Figure 4. Horizontal displacement of 14th story with 3 type of moveable slab arrangement and without SMD due to sinusiodal signal.

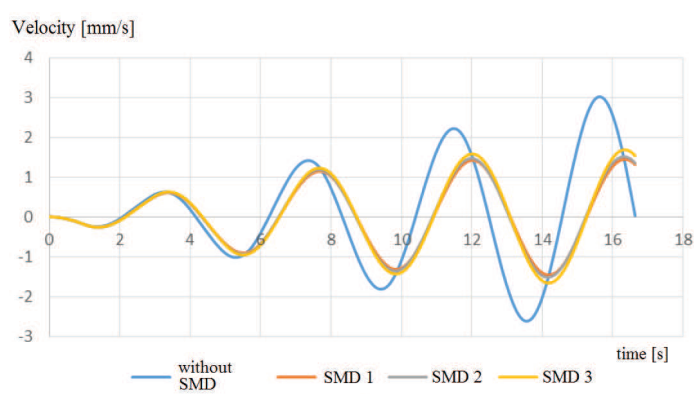

Figure 5. Horizontal velocity of 14th story with 3 type of moveable slab arrangement and without SMD due to sinusiodal signal.

duces (in average) the largest for SMD 1 by $55 \%$ and less reduced is SMD 3 by $46 \%$ as shown in Table 2 . Acceleration of each story reduces (in average) 59\%, 57\% and 52\% by configuration SMD 1, SMD 2 and SMD 3, respectively (Table 3).

Figures 4 to 6 show the displacement, velocity and acceleration of topfloor due to harmonic ground motion. It is shown all variation of SMD placement gives satisfying reduction of responses.

Considering the comfort of inhabitant, acceleration of floor that act as rigid floor and as moveable slab is compared in Figure 7. The amplitude of acceleration reduce insignificantly but it shows frequency shifting.

Stories responses that are displacement, velocity and acceleration, show that optimum configuration is SMD 1.

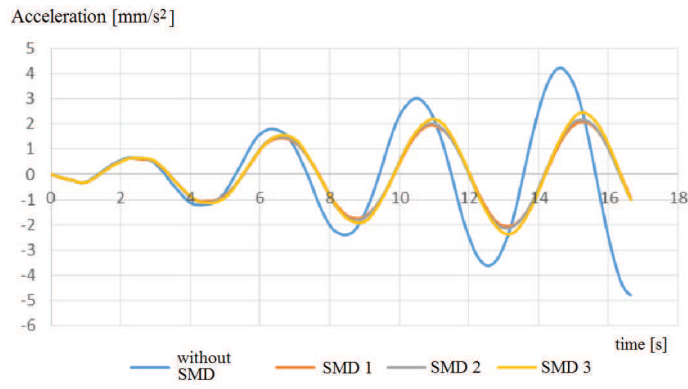

Figure 6. Horizontal acceleration of 14th story with 3 type of moveable slab arrangement and without SMD due to sinusiodal signal.

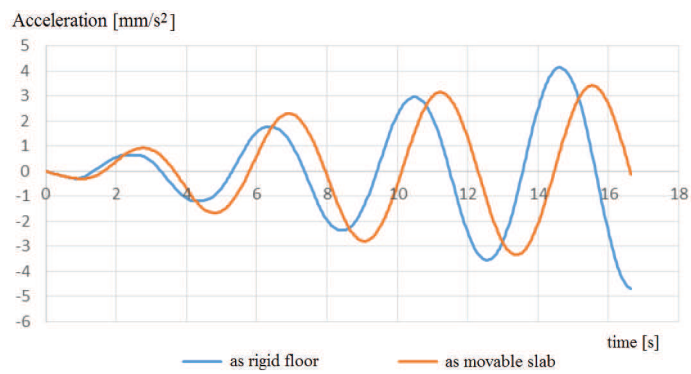

Figure 7. Acceleration of 13th story slab as self mass damper and as rigid floor due to sinusiodal signal.

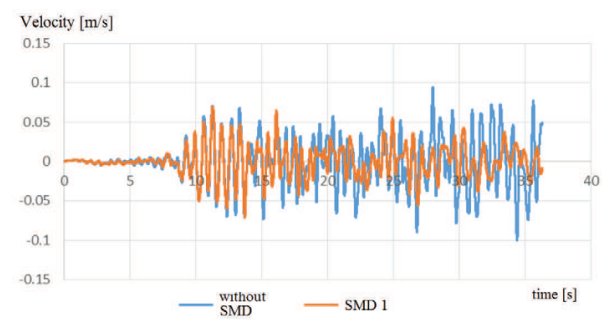

Figure 8. Horizontal velocity of 14th story with and without SMD due to Denpasar signal.

\subsection{Due to Denpasar ground acceleration}

The building with self mass damper in 13th, 12th, 10th and 9th floors (SMD 1) imposed by Denpasar ground acceleration. Figure 8 compares the velocity at top floor of building with self damper and without SMD. In some early 15 seconds the amplitude is quite the same, but afterward velocity reduced significantly with maximum $50 \mathrm{~mm} / \mathrm{s}$.

Comparison of 13th floor as movable slab and as rigid floor is shown in Figures 9, 10 and 11. As movable slab, 13th floor displaces rather stable than as rigid slab. Even though the amplitude of displacement larger at some point (Figure 9), but velocity and acceleration reduced significantly (Figures 10 and 11).

\subsection{Due to El Centro ground acceleration}

Due to El Centro ground acceleration, in some early minutes building with SMD 1 configuration has slightly 


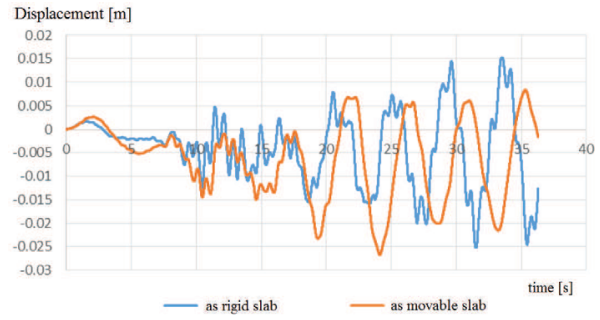

Figure 9. Displacement of 13th story slab as self mass damper and as rigid floor due to Denpasar signal.

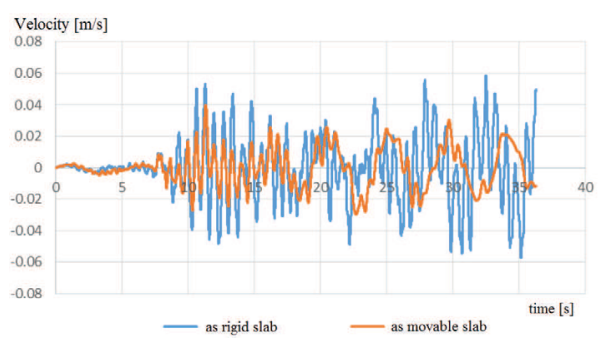

Figure 10. Velocity of 13th story slab as self mass damper and as rigid floor due to Denpasar signal.

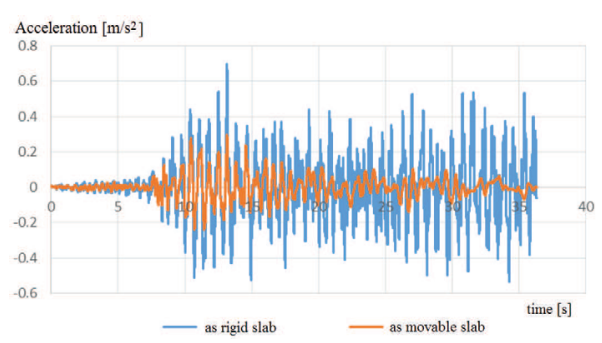

Figure 11. Acceleration of 13th story slab as self mass damper and as rigid floor due to Denpasar signal.

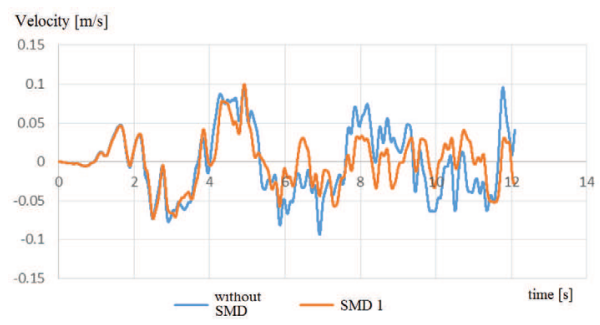

Figure 12. Horizontal velocity of 14 th story with and without SMD due to El Centro signal.

smaller velocity at top floor (Figure 12). Significant velocity reduction happen after 5 seconds, with maximum velocity from $90 \mathrm{~mm} / \mathrm{s}$ reduces to $50 \mathrm{~mm} / \mathrm{s}$.

Vibration of 13th floor as movable slab and as rigid slab is compared in Figures 13, 14 and 15. As movable slab, the displacement of 13th floor is larger at some point compared to its displacement as rigid slab. After $6 \mathrm{sec}-$ onds, the displacement shows significant reduction. Similar behaviour has been observed with velocity response of

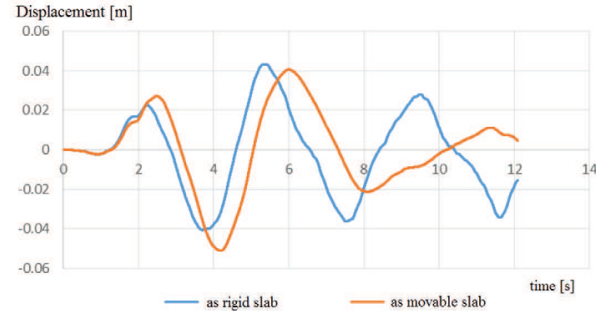

Figure 13. Displacement of 13th story slab as self mass damper and as rigid floor due to El Centro signal.

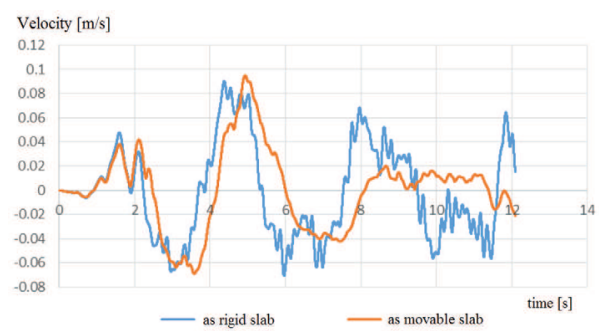

Figure 14. Velocity of 13th story slab as self mass damper and as rigid floor due to El Centro signal.

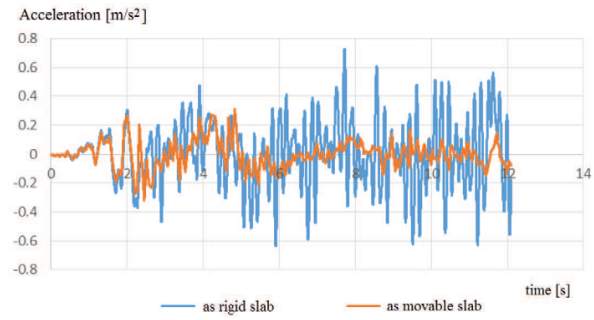

Figure 15. Acceleration of 13th story slab as self mass damper and as rigid floor due to El Centro signal.

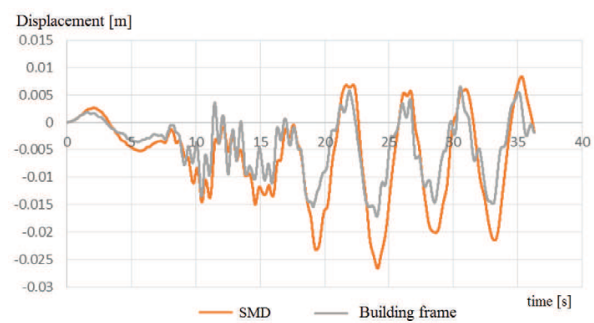

Figure 16. Displacement of moving slab at 13th story and frame due to Denpasar signal.

13th floor. Meanwhile, acceleration reduced significantly from the beginning.

Figures 16 and 17 plot the displacement of moving slab in 13th story along side the displacement of corresponding structural member. The plot described the minimum gap needed to allow the movable slab travel without pounding structural member. Simulation with Denpasar ground motion gives minimum gap of $13 \mathrm{~mm}$ (Figure 16), and with El Centro ground motion gives minimum gap of $30 \mathrm{~mm}$ (Figure 17). 


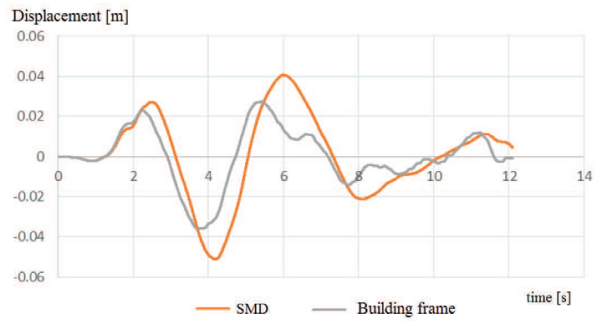

Figure 17. Displacement of moving slab at 13th story and frame due to Elcentro signal.

Outside range of 4.2-5.8s simulation by El Centro signal (Figure 14), top floor velocity is not more than $40 \mathrm{~mm} / \mathrm{s}$ as required by DIN 4150 [5].

Acceleration of movable 13th floor due to both Denpasar and El Centro ground acceleration decrease from $750 \mathrm{~mm} / \mathrm{s}^{2}$ to $350 \mathrm{~mm} / \mathrm{s}^{2}$.

To avoid pounding between movable slab and structural member of building, small gap should be provided when applying movable slab floor.

\section{Summary}

1. Application of SMD for three placement variation reduced dynamic responses more than $50 \%$ in resonance frequency.

2. The optimal placement of self mass damper conforms to the first translational mode of the building.

3. Although maximum displacement of movable 13th floor slab is larger compared to rigid 13th floor slab, the vibration of movable slab is more stable.

4. Applied SMD gives larger reduction on the building's displacement, velocity, and acceleration in re- sponse to the Denpasar ground acceleration rather than the El Centro 1940.

5. The movable slab works good as self mass damper to reduce velocity and acceleration of floor. It leads to increased comfort level of tenant.

6. Using the functional floor as damping instrument is a smart idea. The building can keep its valuable space whilst also maintaining the comfort level.

\section{Acknowledgements}

The authors would like to thank the Structural Laboratory, Civil Engineering Department Unpar for support on SAP2000.

\section{References}

[1] A.Y. Tuan, G.Q. Shang, Journal of Applied Science and Engineering 17, 141 (2014)

[2] R. Kidokoro, Self Mass Damper (SMD): Seismic Control System Inspired by the Pendulum Movement of an Antique Clock, in The 14th World Conference on Earthquake Engineering (2008)

[3] C. Petersen, Schwingungsdämpfer im Ingenieurbau (Maurer Söhne, München, 2001)

[4] D.R. Widarda, E. Zulkifli, F.A.T. Prabowo, T.D. Akbar, Application Of Tuned Mass Damper On Suspension Footbridge, in Proceeding the 6th Civil Engineering Conference in Asia Region: Embracing the Future through Sustainability, edited by I. Imran, Rildova, E. Zulkifli, D.R. Widarda (2013), pp. TS1 113-120

[5] DIN, DIN 4150-3. Erschüterungen im Bauwesen. Teil 3: Einwirkungen auf bauliche Anlagen (1999) 
Table 1. Maximum story displacement (m)

\begin{tabular}{llllllll}
\hline & \multicolumn{7}{c}{ Horizontal displacement(m) } \\
\cline { 2 - 7 } & without SMD & SMD 1 & Reduction & SMD 2 & Reduction & SMD 3 & Reduction \\
\hline 14th story & 2.119 & 1.006 & $52.52 \%$ & 1.048 & $50.54 \%$ & 1.166 & $44.97 \%$ \\
\hline 13th story & 2.077 & 0.982 & $52.72 \%$ & 1.03 & $50.41 \%$ & 1.139 & $45.16 \%$ \\
\hline 12th story & 2.011 & 0.943 & $53.11 \%$ & 0.999 & $50.32 \%$ & 1.094 & $45.60 \%$ \\
\hline 11th story & 1.917 & 0.89 & $53.57 \%$ & 0.95 & $50.44 \%$ & 1.035 & $46.01 \%$ \\
\hline 10th story & 1.795 & 0.82 & $54.32 \%$ & 0.88 & $50.97 \%$ & 0.966 & $46.18 \%$ \\
\hline 9th story & 1.648 & 0.733 & $55.52 \%$ & 0.799 & $51.52 \%$ & 0.887 & $46.18 \%$ \\
\hline 8th story & 1.481 & 0.644 & $56.52 \%$ & 0.706 & $52.33 \%$ & 0.799 & $46.05 \%$ \\
\hline 7th story & 1.296 & 0.554 & $57.25 \%$ & 0.599 & $53.78 \%$ & 0.7 & $45.99 \%$ \\
\hline 6th story & 1.093 & 0.461 & $57.82 \%$ & 0.491 & $55.08 \%$ & 0.583 & $46.66 \%$ \\
\hline 5th story & 0.877 & 0.366 & $58.27 \%$ & 0.387 & $55.87 \%$ & 0.451 & $48.57 \%$ \\
\hline 4th story & 0.652 & 0.27 & $58.59 \%$ & 0.285 & $56.29 \%$ & 0.324 & $50.31 \%$ \\
\hline 3rd story & 0.433 & 0.178 & $58.89 \%$ & 0.187 & $56.81 \%$ & 0.211 & $51.27 \%$ \\
\hline 2nd story & 0.229 & 0.093 & $59.39 \%$ & 0.098 & $57.21 \%$ & 0.11 & $51.97 \%$ \\
\hline 1st story & 0.068 & 0.027 & $60.29 \%$ & 0.029 & $57.35 \%$ & 0.032 & $52.94 \%$ \\
\hline Average & & & $56.34 \%$ & & $53.50 \%$ & & $47.70 \%$ \\
\hline
\end{tabular}

Table 2. Maksimum story velocity $(\mathrm{m} / \mathrm{s})$.

\begin{tabular}{llllllll}
\hline & \multicolumn{7}{c}{ Horizontal velocity (m/s) } \\
\cline { 2 - 8 } & $\begin{array}{l}\text { without } \\
\text { SMD }\end{array}$ & SMD 1 & Reduction & SMD 2 & Reduction & SMD 3 & Reduction \\
\hline 14th story & 3.018 & 1.46 & $51.62 \%$ & 1.517 & $49.73 \%$ & 1.685 & $44.17 \%$ \\
\hline 13th story & 2.957 & 1.425 & $51.81 \%$ & 1.489 & $49.64 \%$ & 1.645 & $44.37 \%$ \\
\hline 12th story & 2.859 & 1.368 & $52.15 \%$ & 1.444 & $49.49 \%$ & 1.58 & $44.74 \%$ \\
\hline 11th story & 2.721 & 1.288 & $52.66 \%$ & 1.371 & $49.61 \%$ & 1.495 & $45.06 \%$ \\
\hline 10th story & 2.543 & 1.185 & $53.40 \%$ & 1.267 & $50.18 \%$ & 1.396 & $45.10 \%$ \\
\hline 9th story & 2.329 & 1.057 & $54.62 \%$ & 1.147 & $50.75 \%$ & 1.283 & $44.91 \%$ \\
\hline 8th story & 2.089 & 0.926 & $55.67 \%$ & 1.012 & $51.56 \%$ & 1.156 & $44.66 \%$ \\
\hline 7th story & 1.824 & 0.795 & $56.41 \%$ & 0.856 & $53.07 \%$ & 1.013 & $44.46 \%$ \\
\hline 6th story & 1.535 & 0.661 & $56.94 \%$ & 0.7 & $54.40 \%$ & 0.843 & $45.08 \%$ \\
\hline 5th story & 1.229 & 0.523 & $57.45 \%$ & 0.551 & $55.17 \%$ & 0.653 & $46.87 \%$ \\
\hline 4th story & 0.913 & 0.384 & $57.94 \%$ & 0.404 & $55.75 \%$ & 0.469 & $48.63 \%$ \\
\hline 3rd story & 0.605 & 0.253 & $58.18 \%$ & 0.266 & $56.03 \%$ & 0.305 & $49.59 \%$ \\
\hline 2nd story & 0.32 & 0.132 & $58.75 \%$ & 0.14 & $56.25 \%$ & 0.16 & $50.00 \%$ \\
\hline 1st story & 0.095 & 0.039 & $58.95 \%$ & 0.041 & $56.84 \%$ & 0.047 & $50.53 \%$ \\
\hline Average & & & $55.47 \%$ & & $52.75 \%$ & & $46.30 \%$ \\
\hline & & & & & & & \\
\hline
\end{tabular}


Table 3. Maksimum story acceleration $\left(\mathrm{m} / \mathrm{s}^{2}\right)$

\begin{tabular}{llllllll}
\hline & \multicolumn{7}{c}{ Horizontal acceleration $\left(\mathrm{m} / \mathrm{s}^{2}\right)$} \\
\cline { 2 - 8 } & $\begin{array}{l}\text { without } \\
\text { SMD }\end{array}$ & SMD 1 & Reduction & SMD 2 & Reduction & SMD 3 & Reduction \\
\hline 14th story & 4.775 & 2.09 & $56.23 \%$ & 2.168 & $54.60 \%$ & 2.45 & $48.69 \%$ \\
\hline 13th story & 4.688 & 2.038 & $56.53 \%$ & 2.136 & $54.44 \%$ & 2.392 & $48.98 \%$ \\
\hline 12th story & 4.554 & 1.96 & $56.96 \%$ & 2.081 & $54.30 \%$ & 2.291 & $49.69 \%$ \\
\hline 11th story & 4.365 & 1.852 & $57.57 \%$ & 1.987 & $54.48 \%$ & 2.157 & $50.58 \%$ \\
\hline 10th story & 4.11 & 1.717 & $58.22 \%$ & 1.849 & $55.01 \%$ & 2.006 & $51.19 \%$ \\
\hline 9th story & 3.783 & 1.548 & $59.08 \%$ & 1.688 & $55.38 \%$ & 1.84 & $51.36 \%$ \\
\hline 8th story & 3.407 & 1.367 & $59.88 \%$ & 1.495 & $56.12 \%$ & 1.661 & $51.25 \%$ \\
\hline 7th story & 2.986 & 1.178 & $60.55 \%$ & 1.272 & $57.40 \%$ & 1.457 & $51.21 \%$ \\
\hline 6th story & 2.527 & 0.982 & $61.14 \%$ & 1.044 & $58.69 \%$ & 1.216 & $51.88 \%$ \\
\hline 5th story & 2.035 & 0.778 & $61.77 \%$ & 0.824 & $59.51 \%$ & 0.941 & $53.76 \%$ \\
\hline 4th story & 1.52 & 0.573 & $62.30 \%$ & 0.609 & $59.93 \%$ & 0.674 & $55.66 \%$ \\
\hline 3rd story & 1.015 & 0.381 & $62.46 \%$ & 0.404 & $60.20 \%$ & 0.439 & $56.75 \%$ \\
\hline 2nd story & 0.543 & 0.204 & $62.43 \%$ & 0.212 & $60.96 \%$ & 0.232 & $57.27 \%$ \\
\hline 1st story & 0.164 & 0.061 & $62.80 \%$ & 0.063 & $61.59 \%$ & 0.069 & $57.93 \%$ \\
\hline Average & & & $59.85 \%$ & & $57.33 \%$ & & $52.59 \%$ \\
\hline
\end{tabular}

